\title{
Trabalho em altura X Acidentes de trabalho na Construção Civil
}

\author{
Work at Height X Construction Accidents at Work
}

\author{
Rodrigo Domis Camargo ${ }^{\dagger}$, Enilson Salino Braga ${ }^{\dagger}$, Alex Franco Ferreira ${ }^{\ddagger}$ José Thomaz de \\ Carvalho ${ }^{*}$
}

Como citar esse artigo. Camargo, RD; Braga, ES; Ferreira, AF; Carvalho, JT. Trabalho em altura $\mathrm{x}$ acidentes de trabalho na construção civil. Revista Teccen. 2018 Jul./Dez.; 11 (2): 09-15.

\section{Informações gerais}

As dificuldades de adaptação às condições de trabalho resultam em danos ao estado geral de saúde, tratando aqui sobre a segurança do trabalho na Construção Civil (WALDHEIM, 2015).

Tratando da baixa em questão da construção civil no atual cenário econômico, pode-se verificar que em obras no ramo civil os números de acidentes não diminuem. Verifica-se que as principais causas desses acidentes são devido aos atos inseguros praticados pelos

\section{Resumo}

Tratando da parte introdutória do trabalho, o estudo tem como relevância apresentar as profundas transformações na área da construção civil envolvendo serviços em altura. O objetivo do trabalho está em mostrar o guia prático da boa conduta das políticas dos riscos ocupacionais dos trabalhadores da construção civil, demonstrando a importância através de treinamentos, orientações e até mesmo o incentivo relacionados aos métodos corretos dos serviços que serão executados na construção civil. A realização do trabalho está no campo da conscientização e a capacitação dos indivíduos para que possam reconhecer as possibilidades de riscos em um ambiente de trabalho na indústria da construção civil. A linha do estudo está nos acidentes de trabalho relacionados às quedas com diferenças de níveis na construção civil. Apesar da grande quantidade de legislação que trata da questão do trabalho no Brasil, ainda são muito reduzidos o interesse e o conhecimento do cidadão comum acerca da temática. Pode ser observado que o acidente de trabalho ocorre pelo exercício do trabalho a serviço da empresa. Foram verificados os riscos, ações preventivas através da gestão da segurança proporcionado controle de riscos no papel do SESMT (Serviço Especializado em Engenharia de Segurança e em Medicina do Trabalho). $\mathrm{O}$ artigo apresenta as medidas de controle envolvendo o homem no ambiente de trabalho minimizando os riscos através de recursos como proteção individual em na busca de fazer com que os indivíduos (colaboradores) adquiram hábitos e posturas, seguindo regras e não se expondo aos riscos inerentes ao trabalho em altura na construção civil. Assim pode observar se tiver um bom monitoramento envolvendo a conscientização do uso dos equipamentos e um bom treinamento irá minimizar riscos de morte em acidentes altura.

Abstract

In dealing with the introductory part of the work, the study has as relevance to present as deep transformations in the area of civil construction involving services in height. The objective of the work is in view of the Practical Guide to Good Conduct of Occupational Hazards Policies of Construction Workers, demonstrating the importance through training, guidance and even incentive related to correct methods of services that are performed in construction. The realization of the work is in the field of awareness and the ability to recognize risk possibilities in a work environment in the construction industry. One line of the study is in work accidents related to falls with levels in construction. Despite the large amount of law that deals with the subject of work, it does not exist in Brazil, they are still very reduced in the interest and knowledge of the common citizen on the subject. It can be observed that the work accident by means of the exercise of the work at the service of the company. SESMT (Specialized Service in Safety Engineering and Occupational Medicine) is verified by the risks, preventive actions through the security management and paperless risk control. The article presents as control measures involving the man in the work environment minimizing the risks through resources such as individual protection in the search to make the users (employees) acquire habits and postures, following rules and not exposing themselves to the Inherent risks to the work in height in the civil construction.

Keywords: Civil Construction, Training, Safety.

colaboradores, como também pela ineficácia do sistema de Gestão de Segurança (WALDHEIM, 2015).

A gestão de segurança pode contribuir sobremaneira para desenvolver o hábito de segurança do trabalho com criatividade, sensibilidade e conhecimento do comportamento humano que podem significar importantes contribuições afins (WALDHEIM, 2015).

É importante salientar que as organizações nada mais são do que um complexo sistema sociotécnico, então para compreender a formação e a dinâmica da organização, o SESMT (Serviços Especializado em Engenharia de Segurança e em Medicina do Trabalho,

Afiliação dos autores: †Curso de Graduação em Engenharia Civil, Universidade de Vassouras, RJ, Brasil;

\$Curso de Graduação em Engenharia Elétrica, Universidade de Vassouras, RJ, Brasil.

*Email para correspondência: jose.thomaz@uol.com.br 
2012) influenciará nas implantações das ferramentas de controle de gestão utilizadas para prevenção de acidentes.

Em relação a ações educativas que propiciam os hábitos saudáveis entre os trabalhadores, o estudo estará apresentando métodos aplicados de forma a promover a adequada integração não apenas no desempenho de tarefas, mas buscando-se atender junto ao RH (Recursos Humanos) uma integração que envolve fatores, sociais e psicológicos (MONTEIRO, 2011).

O estudo não pretende substituir a engenharia pela medicina, porém a conscientização do uso do EPI é uma segurança interventiva, onde vale ressaltar que o órgão como a CIPA (Comissão Interna de Prevenção de Acidentes) é uma supervisão de nível gerencial para que todos os envolvidos sintam-se responsáveis pela segurança, atuando diretamente aos funcionários de forma proativa e reativa às recomendações necessárias (MONTEIRO, 2011).

Vale ressaltar que o sucesso da intervenção passa pelo comprometimento dos níveis gerenciais, pois, ainda que o trabalho estabeleça proposta de uma questão investigativa, permitirá e ainda apoiará as ações dos funcionários com mais responsabilidades.

A atividade de prevenção pode e deve estar sempre presente nos setores de produção e manutenção, pois os custos humanos e/ou materiais causados por acidentes do trabalho podem ser muitas vezes superiores a esse valor investido inadequadamente.

O objetivo do presente estudo é a investigação de riscos de acidentes envolvendo o trabalho em altura na construção civil, buscando ressaltar os procedimentos necessários de um gestor de segurança para minimizar os acidentes, e atuar diretamente na segurança de trabalho, demonstrando a importância através de treinamentos, orientações e até mesmo o incentivo relacionados aos métodos corretos dos serviços que serão executados na construção civil.

O equipamento de proteção individual (EPI) na adequação da NR-6, 2010 proporciona mais segurança aos trabalhadores cumprindo a legislação trabalhista.

\section{Segurança no trabalho}

Sabe-se que a segurança dos trabalhadores e a saúde são contextos muito importantes, para que o mesmo possa produzir com segurança. Assim, antes de quaisquer atributos, pode-se ver a questão da segurança no trabalho como um ponto de referência, que tange e configura as empresas que zelam pela qualidade dos serviços que executam.

Assim como em várias atividades do processo construtivo de uma edificação, a segurança do trabalho não caminha isoladamente, e sim apoiada em uma série de medidas que assegura a organização, limpeza, produtividade, higiene, condições adequadas de trabalho e, ainda, a dignidade aos operários.

Segurança no trabalho são a aplicação de medidas educacionais, técnicas e médicas, que têm o objetivo de prevenir acidente, eliminando condições adversas à segurança do trabalhador, adquirindo práticas de prevenção regidas pelas Normas Regulamentadoras (NRs), que são exigidas pelo Ministério do Trabalho e Emprego.

"As NRs referentes à segurança e medicina do trabalho devem ser de observância obrigatória pelas empresas privadas e públicas de administração direta e indireta, que possuem empregados regidos pela Consolidação das Leis do Trabalho - CLT" (BRASIL, 2009).

Pode-se destacar que a Legislação de Segurança foi sendo desenvolvidas para trazer melhores condições de serviços. Assim as foram estabelecidas leis de proteção à integridade física dos trabalhadores, numa tentativa de preservar o novo modo de produção, leis como a "Lei de Saúde Moral dos Aprendizes" em (1802), limite de 12 horas por dia na Inglaterra que também proibia trabalho noturno, além de exigirem ventilações no ambiente e a Lei das Fábricas (1833) também na Inglaterra , primeira norma eficiente no campo de proteção de trabalho e que fixava em 9 anos a idade mínima para o trabalho, proibia o trabalho noturno para menores de 18 anos e exigia exames médicos de todas as crianças trabalhadoras (RODRIGUES, 1993).

Para Campos (2001), uma Lei muito importante para as condições de trabalho foi editada em 1862, a qual destacava a regulamentação da higiene do trabalho, devido a segurança a Lei dos Equipamentos de Proteção foi aprovada em 8 de junho de 1978, sendo que fora alterada diversas vezes.

A cada dia que passa a busca por ambientes de trabalho mais seguros faz com que os profissionais envolvidos nesta atividade adotem as mais variadas formas de ação, fugindo da utilização apenas das formas clássicas e básicas de atuação. Isso na prática significa que muitas coisas - algumas destas surgem da criatividade e conforme a necessidade da realidade das organizações - outras são, na verdade, antigas técnicas da prevenção que são redescobertas e readequadas aos tempos atuais (PALAZIO, 2009).

Para que a implementação de novas técnicas funcione, a equipe de trabalho em um canteiro de obras deve estar em sintonia com os riscos existentes, e todos devem ser conscientizados e capacitados sobre as medidas preventivas para evitarem os acidentes, diminuindo assim, os custos para empresa e problemas para o empregado.

Os acidentes de trabalho representam altos custos para a empresa, a sociedade e para o próprio trabalhador. Se considerados os custos econômicos, estes são dificilmente calculáveis devido à influência 
de inúmeros fatores, inclusive custos humanos que são transformados em valores econômicos, mas como mensurar uma invalidez para o trabalho ou um acidente fatal (BRITO, 1997).

O que se pode ainda destacar é a forma adequada e prevista em questão a segurança de trabalho, envolvendo os perigos, para que seja desenvolvida uma gestão de forma a garantir que os operários desempenhem as suas atividades com cautela, eliminando qualquer tipo de risco eminente, evitando-se assim as ocorrências de acidentes do trabalho e doenças ocupacionais.

\section{Acidentes do Trabalho}

Uma das principais causas de acidentes de trabalho grave e fatal relaciona-se de forma direta com os atos inseguros e as condições inseguras existentes nos ambientes de trabalho. $\mathrm{O}$ estudo aborda sobre os acidentes de queda em altura, o que torna preocupante tais acidentes nas atividades de construção civil (WALDHEIM, 2015).

O acidente não é tratado como apenas os ferimentos ou lesões ou até mortes, mas há várias preocupações legais que podem repercutir a empresa além do custo gerado pelo acidente.

Segundo o Art. 19 da Lei $\mathrm{n}^{\circ}$ 8.213/91, o esclarecimento legal sobre o acidente de trabalho "é o que ocorre pelo exercício do trabalho a serviço da empresa, [...] provocando lesão corporal ou perturbação funcional que cause morte ou a perda ou redução permanente ou temporária, da capacidade para o trabalho".

Conforme Rocha (2013) enuncia, devido aos poucos conhecimentos dos trabalhadores da construção civil, da periculosidade e também da falta de atenção as instruções passadas pelos seus gestores, sendo estas não bem assimiladas, os riscos tornam-se mais visíveis.

$\mathrm{Na}$ construção civil existem diferentes níveis de trabalhadores, na grande maioria são trabalhadores de baixa escolaridade, com vidas menos regradas, (bebidas, falta de descanso entre outros perfis) o que podem submeter tais trabalhadores aos riscos de um ambiente de trabalho.

No contexto apresentado por Salim (2011), os trabalhos em altura, envolvem instrumentos que precisam de mais atenção, tratando dos trabalhos em escadas, andaimes, serviços realizados em sacadas, telhados, chaminés, coberturas, montagem de estruturas metálicas, pré-moldadas, serviços em elevadores entre outros.

As medidas de proteção estão elencadas em normas e regulamentos obrigatórios para evitar os acidentes, a partir das proteções coletivas e individuais.

\section{Conceito de Proteção coletiva}

Tratando da proteção coletiva, essas visam proteger os colaboradores ao mesmo tempo. Conforme as Normas Regulamentadoras (MTE) elas devem ser aplicadas primeiramente, caso os riscos não podem ser totalmente eliminados, deverão ser adotados os Equipamentos de Proteção Individual.

\section{Conceito de Proteção individual}

Conforme NR 06 - Equipamentos de Proteção Individual (2007), os mesmos são importantes, e precisam estar em boas condições, entende-se que os equipamentos individuais são dispositivos de uso individual utilizado pelos trabalhadores destinados, à proteção dos riscos que podem comprometer a segurança e a saúde dos trabalhadores.

Não obstante, sobre o setor de construção civil, os grupos devem estar envolvidos na utilização dos EPI's listados pela NR-6 (2007), porque trata-se de um setor que engloba atividades que para Monteiro (2011) consistem em atividades que apresentam riscos devido o contato com águas, com alturas, com eletricidade, além dos riscos causados pelos trabalhos de escavações, de demolições, de alvenarias, de aplicação de pavimentos e revestimentos, de carpintaria e de serralharia que englobam as atividades desenvolvidas na Construção Civil.

A NR-6 (2007) ressalta que a proteção da cabeça é feita através do uso de capacetes, capuz ou bala clave. Sendo utilizados em obras de pequeno porte apenas os que protegem o crânio contra impactos, como mostra a Figura 1.

Figura 1. Capacete para proteção contra impactos de objetos sobre o crânio.
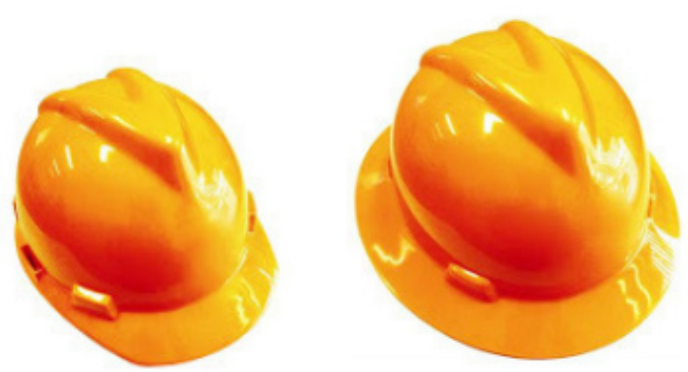

Fonte: Nestor Waldhelm Neto 2015.

Já Ramos (2009), destaca que os óculos são EPI's, conforme a NR-6, os mesmos correspondem aos dispositivos responsáveis pela proteção dos olhos contra respingos de produtos químicos, luminosidade, radiações, poeiras e trabalhos com objetos perfurantes. Um exemplo deste EPI é apresentado na Figura 2. 
Para Silva (2009), os protetores auriculares correspondem a equipamentos destinados a proteção dos trabalhadores que trabalham em locais com ruído elevado. Um exemplo de protetor auricular é apresentado na Figura 3. A NR-6 (2007) ainda enuncia sobre a proteção dos membros superiores, referindo-se as luvas e do membro de proteção inferiores referindose aos calçados.

Conforme a NR 06 (2007), os equipamentos devem ser fornecidos e comercializados com CA (Certificado de Aprovação) emitida pelo órgão competente.

A empresa deve fornecer gratuitamente aos trabalhadores, objetivando a proteção dos mesmos na execução das suas atividades. Aqui tratando do trabalho em altura, propriamente dito, na construção civil, os equipamentos contra queda em altura, são equipamentos cuja proteção, é composta de fitas, fivelas de engate, fivelas de encaixes com pontos de conexão para melhor ajuste, tratando do cinto de segurança tipo paraquedista regido pela norma regulamentadora - ABNT NBR 15835/2010 como mostra a Figura 4.

O talabarte é um equipamento que serve para conectar o cinto de segurança ao ponto de ancoragem, que pode ser fabricado em cabo de aço, correntes, fita sintética e corda sintética, é regido pelas normas ABNT NBR 15834/2013 e ABNT NBR 14629/ 2013. Exemplos dos mais comercializados são apresentados na Figura 5.

Figura 2. Óculos par Figura 2: Óculos para proteção dos olhos. a proteção dos olhos.

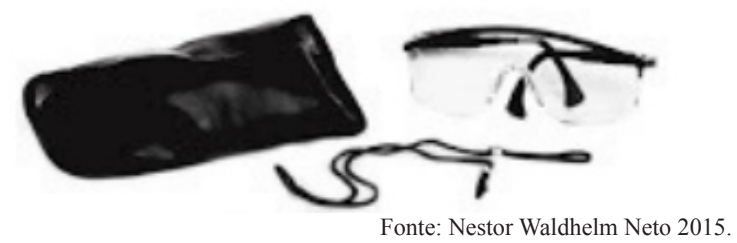

Figura 3. Protetor auditivo do tipo circum- auricular.
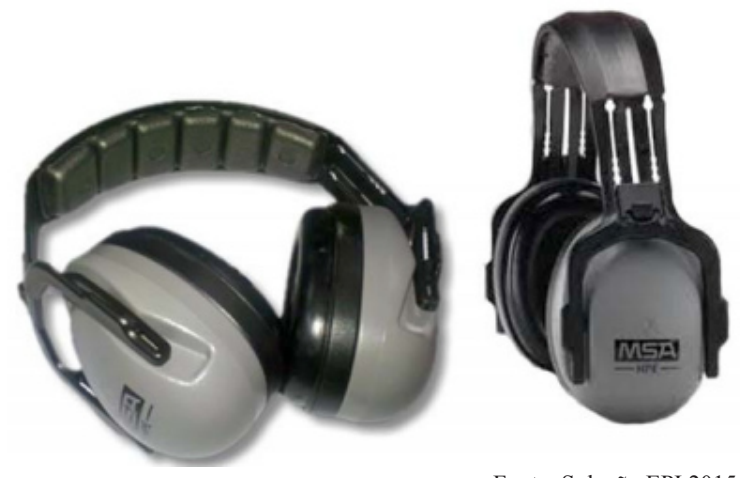

Fonte: Solução EPI 2015.
Figura 4. Cinto paraquedista e cinto 2 pontos.
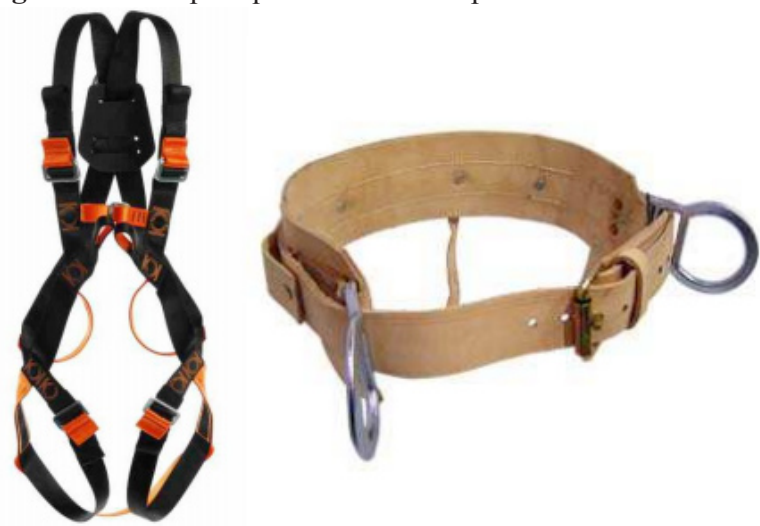

Fonte: Site Altiseg de 2012

Figura 5. Cintos de segurança Talabarte.
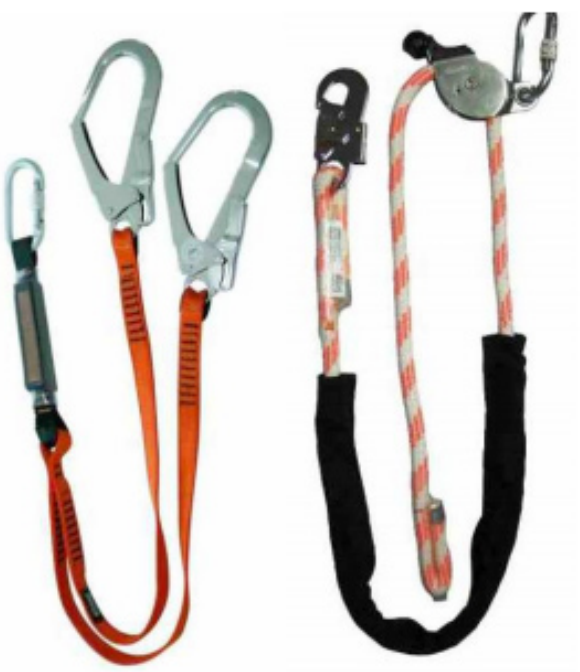

Fonte: Site Altiseg de 2012.

Figura 6. Travas quedas.
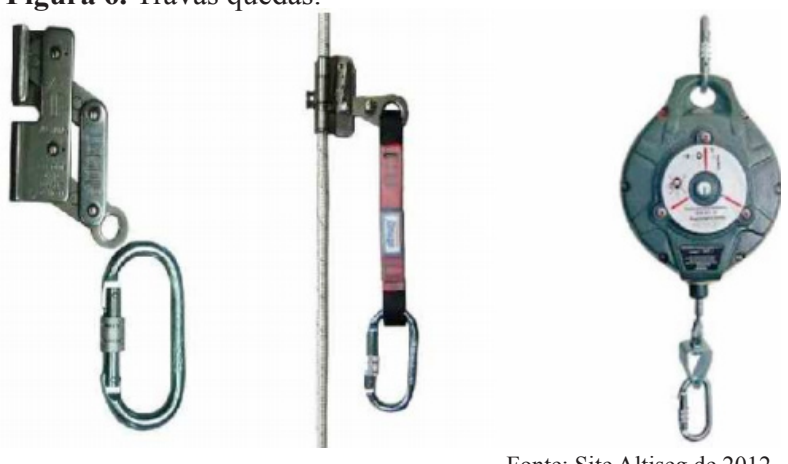

Fonte: Site Altiseg de 2012.

\section{Trava quedas}

Travas quedas, conforme apresenta a Figura 6, é um dispositivo que funciona como Bloqueio automático na existência da queda. Deve movimentar-se sobre a 
linha de vida rígida ou flexível. Existem diversos tipos de trava quedas, podendo ser retrátil onde sua liberação e retrocesso são automáticos e bloqueiam no caso de quedas. São utilizados nas atividades que necessitam maior movimentação dos colaboradores.

Considerando que os equipamentos apresentados são importantes, não se deve omitir a importância dos equipamentos adicionais: como as luvas, botas, capacetes entre outros que fazem parte da realização dos serviços em altura.

\section{Prevenção de acidentes}

O setor de Construção Civil na parte de legislação tem há obstáculos, pois, as normas são corretas, mas ainda acontecem acidentes. Montenegro e Santana (2008) mencionam sobre a importância do uso de equipamento de proteção individual pelos trabalhadores de Construção Civil é eficazmente importante, pois são feitos, para evitar lesões e doenças relacionadas ao trabalho.

Ainda segundo a Lei 8.213/1991, a acidentes do trabalho, a mesma expõe que a empresa é a organização responsável pelo suprimento e uso das medidas individuais e coletivas de proteção, esclarecendo assim as informações necessárias sobre os riscos das operações a serem desempenhadas, do produto a manusear e pela saúde e segurança do trabalhador.

Logo, o não cumprimento das normas regulamentadoras representa uma infração que remete a pena, passível a ser punida ou notificada.

Vale ressaltar, que ainda encontram-se empresas que vem descumprindo as principais determinações legais, apontando sobre a questão do alto custo para implementação das medidas preventivas e embasado na importância de investimentos em prevenção, devemos ter noção do conhecimento de que a prevenção não é apenas a melhor opção, como também entender que o seu investimento é menos oneroso do que os custos que se deve arcar com a cura de um acidentado, dessa maneira, os fatores de segurança e os lucros das empresas devem caminhar juntos, lado a lado, tendo em vista que a defesa da implantação da segurança do trabalho nas diferentes instâncias de uma organização, sempre será a melhor opção para evitar os incidentes e acidentes nos ambientes laborais.

\section{Causas de acidentes}

O uso dos EPI's é uma estratégia de ação preventiva fundamental, sendo indispensável para a segurança dos trabalhadores, pois visa proteger e reduzir os riscos existentes no ambiente de trabalho, como também amenizar as sequelas que venham ocorrer no caso de acidentes, podendo ser ferramentas determinantes no que se refere a salvar vidas dos trabalhadores. Uma das formas de garantir o uso dos EPI's pelos trabalhadores da Construção Civil é a fiscalização das atividades desenvolvidas no setor, pois assegura a qualidade e segurança do empreendimento durante a sua fase de construção, evitando assim as falhas no sistema construtivo.

Pode considerar que os acidentes de trabalho envolvendo altura, são causados por algumas irregularidades dos colaboradores e a falta de monitoramento do chefe de obra. Podem ser observadas como um ponto principal das falhas internas na construção civil, conforme Cardela (2010) apresenta:

Perda de equilíbrio, passos em falsos escorregões entre outros; falta de proteção, por exemplo, o guardacorpo; falhas de instalações ou dispositivos de proteção; métodos incorretos de trabalho; contato acidental com fios de alta tensão e inaptidão do trabalhador à atividade (Cardela, 2010).

Figura 7. Cenário de quedas sem Equipamentos de Proteção Individual - EPI.

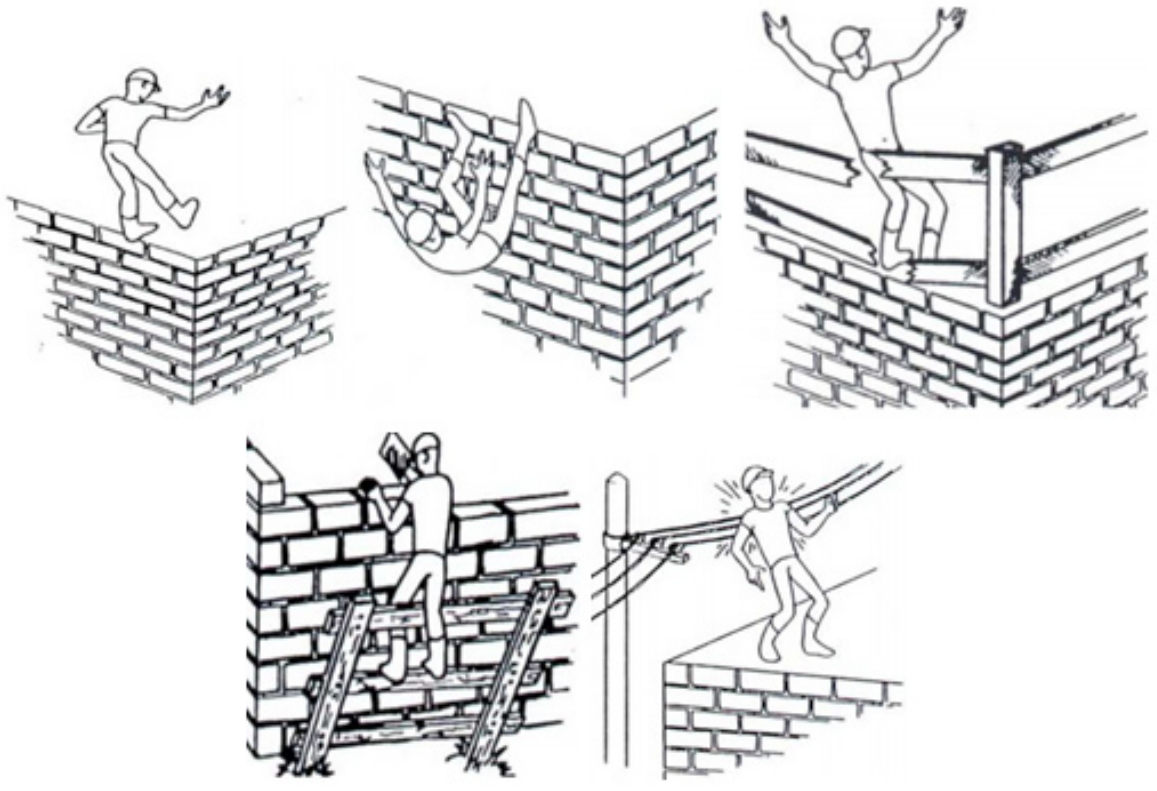


A Figura 7, exemplifica a situação descrita por, Cardela (2010).

Cardela (2010) ainda frisa que a maioria dos acidentes acontece por falta de manutenção das fermentas e também dos treinamentos necessários para os trabalhadores, sendo que, antes de iniciar suas atividades os mesmos expõem-se aos riscos. Entretanto, podem ser citadas algumas falhas internas que demonstram a falta de comprometimento no monitoramento por partes dos responsáveis da empresa.

Quaisquer ferramentas de investigação de acidentes têm como pontos fundamentais a coleta e organização dos fatos. É de fundamental importância dentro de um sistema de segurança do trabalho, a comunicação e investigação dos acidentes, devendo ser feita logo após a ocorrência, de maneira a agilizar o processo de efeito retroativo e incluir os incidentes, com o objetivo de dar um caráter proativo à investigação.

A investigação de acidentes do trabalho no Brasil encontra-se ainda num patamar que considera o acidente como um fenômeno decorrente de falhas técnicas e ou humanas. Essa concepção, indesejavelmente ainda vem prevalecendo em um bom número de empresas brasileiras.

Embora com a criação da Norma Regulamentadora $n^{\circ} 5$ (NR 5-Comissão Interna de Prevenção de acidentes, 1978) que estabelece como objetivo a prevenção de acidentes e doenças decorrentes do trabalho, tornando compatível o trabalho com a preservação da vida e saúde do trabalhador, cujas atribuições faz menção a identificação dos riscos do processo de trabalho, para elaboração de planos de atividades que possibilitem a ação preventiva na solução de problemas. Ainda se percebem investigações extremamente superficiais, fundamentadas no fenômeno monocausal do acidente, nas quais deveria ser determinada a causa apurada do acidente para fins de controle e registro (COSTELLA, 2004).

\section{Certificado de aprovação}

Sobreaquestão de comprovação dosequipamentos de proteção, o EPI precisa passar por aprovação do Ministério do Trabalho e Emprego (MTE, Portaria 3214 de 07 de 1978), onde deverá ser expedido pelo órgão nacional competente em matéria de segurança e saúde no trabalho do MTE, uma vez que o mesmo vai atestar que os EPI's estão em conformidade com as especificações no âmbito do Sistema Nacional de Metrologia ainda a Normalização e Qualidade Industrial (SINMETRO) para um determinado uso e assim com esta certificação é considerado apto para ser comercializado como EPI's (CAMPOS, 2009).

Ainda no mesmo conceito Lima e Gonzaga (2011) frisam que no Departamento de Segurança e Saúde no Trabalho (DSST) é importante que seja estabelecido pelos técnicos ensaios, onde o fabricante ou o importador dos equipamentos devem examinar a documentação que é exigida para emitir ou renovar o C.A. de cada Equipamento de proteção, seja ele individual ou coletivo.

\section{Considerações finais}

A partir das pesquisas realizadas, pode- se perceber que os acidentes do trabalho envolvendo altura são causados por atos inseguros dos colaboradores e por falta de comprometimento no monitoramento por partes dos responsáveis da empresa. A empresa deve conscientizar e capacitar seus colaboradores para que possam reconhecer as possibilidades de riscos em um ambiente de trabalho na indústria da construção civil.

O estudo ainda salienta que a baixa qualificação se dissemina pela prevalência da rotatividade, que por sua vez, são alimentadas pela costumeira substituição de trabalhadores, a absorção de pessoas com menor capacitação ou sem nenhuma experiência profissional pode ser apontada por atraso no setor, assim dentro do estudo somente feitos por referencial teórico, estabeleceu uma análise apenas do conceito protetivo sobre a importância do equipamento de proteção pelas normas NR-6 (2007) e seus conhecimentos.

É percebido que o trabalho ainda precisa ser mais desenvolvido para atentar a uma prevenção dentro das seguranças por meios de planejamentos adequados buscando utilizar trabalhadores que tenham ou não experiência para um novo molde da empresa. Lembrando que o trabalhador motriz é a peça principal para produtividade, assim requer também uma manutenção, conhecimentos e o mais importante conscientização de sua segurança.

\section{Conclusão}

O trabalho em questão cumpre seu objetivo em mostrar um guia prático da boa conduta das políticas dos riscos ocupacionais dos trabalhadores da construção civil, demonstrando a importância através de treinamentos, orientações e até mesmo o incentivo relacionados aos métodos corretos dos serviços que serão executados na construção civil.

Apesar da grande quantidade de legislação que trata da questão do trabalho no Brasil, ainda são extremamente reduzidos o interesse e o conhecimento do cidadão comum acerca da temática.

Foram verificados os riscos, ações preventivas através da gestão da segurança proporcionado controle de riscos no papel do SESMT (Serviço Especializado em Engenharia de Segurança e em Medicina do Trabalho).

Desta forma, este trabalho ressalta a importância 
no campo da conscientização e da capacitação dos indivíduos para que possam reconhecer as possibilidades de riscos em um ambiente de trabalho na indústria da construção civil.

Finalizando, torna-se notório a mazela que o setor vive em questões de investimentos técnicos e financeiros que visem à melhoria dos equipamentos e técnicas aplicadas a atividade laboral, bem como a preservação da vida e melhores condições de trabalho aos funcionários da construção civil, requerendo urgentemente um olhar mais apurado dos órgãos de fiscalização competentes do Ministério do Trabalho.

\section{Referências}

ALTISEG. (2012). Cartilha de Segurança: NR-35 Trabalhos em Altura, Altiseg. (2012). Cartilha de Segurança: Seleção e utilização de EPI para trabalho em altura. Curitiba, 2012.

BRASIL. (1978). Ministério do Trabalho e Emprego. Portaria 3.214 de Jul. 1978. Normas regulamentadoras de segurança e saúde no trabalho - NR-15: Atividades e Operações Insalubres. Brasília, 1978. Acesso em nov, 2001. [online]. Disponível em: Disponível em http://unicamp.sibi.usp.br/bitstream/ handle/SBURI/25460/S0103-84782007000200030.pdf?sequence=1 Acesso 2017.

Brasil, C. D. (2009). IBGE (Instituto Brasileiro de Geografia e Estatística). Pesquisa Nacional por Amostra de Domicílios - PNAD. Diretoria de Pesquisas, Coordenação de Trabalho e Rendimento. Rio de Janeiro, IBGE.

Brito, C. R. G. (1997). Proteção contra acidentes de trabalho em diferença de nível na construção civil. Especialização em Engenharia de Segurança do Trabalho, Universidade Estadual de Ponta Grossa, Ponta Grossa, PR. Disponível em: http://www.segurancaetrabalho.com.br/download/ acidentesrazente.pdf. Acesso em: 13/05/2014 as 10:17minutos. Acesso 2016

Campos, J. L. D.; Campos, A. B. D. (2001). Acidentes do Trabalho, $2^{\text {a }}$ edição, São Paulo: Editora LTR. Disponível em http://civil.uefs.br/DOCUMENTOS/ MARCIMILIA\%20SANTANA\%20DOS\%20SANTOS.pdf Acesso 2017.

Cardella, B. (2010). Segurança no trabalho e prevenção de acidentes: uma abordagem holística: segurança integrada à missão organizacional com produtividade, qualidade, preservação ambiental, e desenvolvimento de pessoas. $1^{a}$. Ed - São Paulo: Atlas. Cinturão de segurança tipo páraquedista talabarte de segurança (NBR 15835). Disponível em: http://www. sindusconsp.com.br/downloads/eventos/2010/normas_171211/normas_1 71211.pdf Acesso em 2017.

Costella, M. F. (2004). Novo modelo de PCMAT baseado nas contribuições do plano de segurança e saúde na construção. I Conferência latino Americana de Construção Sustentável. São Paulo, jul. Disponível em: $<$ http://www. ebah.com.br/content/ABAAAAOVEAF/seguranca-no-trabalho-modelopcmat>. Acesso 2017.

LEI 8.213 de 24/07/91. Disponível em http://www6.senado.gov.br/sicon/ ExecutaPesquisaLegislacao.action. Acesso em 23/08/09. Acesso 2017.

NR 6 - EQUIPAMENTO DE PROTEÇÃO INDIVIDUAL - EPI. Disponível em: portal.mte.gov.br/data/files/.../NR-06\%20(atualizada) \%202010.pdf. Acesso em nov/2014 Disponível em : http://repositorio.roca. utfpr.edu.br/jspui/bitstream/1/3833/1/CT_CEEST_XXIX_2015_07.pdf Acesso 2017

BRASIL. (1978). Ministério do Trabalho e Emprego. NR 05 de 1978 - Comissão Interna de Prevenção de Acidentes.

(1991). Conceito de Acidentes de Trabalho, Art. 19. da Lei 8.213 de 24/07/91. Disponível em: http://eabsaude.com.br/PDFs/conc trabalho.pdf Acesso 2014

Campos, A. A. M. (2009). CIPA - Comissão interna de Prevenção de Acidentes: uma nova abordagem. São Paulo: Editora Senac, $14^{\mathrm{a}}$ Ed. ABNT NBR 14629, Equipamento de proteção individual contra queda de altura Absorvedor de energia Disponível em file://C:/Users/ Usuario/Downloads/1CA9C045886167050E5F60E4C2346C2C\%20(3).pdf Acesso 2017.

ABNT NBR 15834, Equipamento de proteção individual contra queda de altura - Talabarte de segurança Disponível em: file://C:/ Users/Usuario/Downloads/1CA9C045886167050E5F60E4C2346C2C\%20 (3).pdf Acesso2017.

Monteiro, A. R. (2011). Apostila de Agentes de Riscos Químicos. Curso de Engenharia de Segurança do Trabalho da Universidade Federal da Bahia. Salvador, Disponível em: http://bibliodigital.unijui.edu.br:8080/xmlui/ bitstream/handle/123456789/3944/Eduardo\%20Limberger.pdf? sequence $=1$ Acesso 2017.

Palazio, F. T. (2009). Conhecendo e eliminando riscos no trabalho. São Paulo: CNI/SESI/SENAI/IEL.

Ramos, P. (2009). Análise do Programa de Prevenção de Acidentes - Quase Acidente - e a Viabilidade da Aplicação Direta na Construção Civil - Estudo de Caso. Trabalho e Conclusão de Curso submetido à Universidade do Extremo Sul Catarinense - UNESC - no ano de 2009. Trabalho disponível em: www.bib.unesc.net/biblioteca/sumario/000040/000040EF.pdf. Acesso. Acesso 2017.

Rocha, C. A. G. S. C. (2013). Diagnóstico do cumprimento da NR-18 no subsetor edificações da construção civil e sugestões para melhoria da gestão da segurança e saúde ocupacional nas empresas da construção civil. 148p. Dissertação (mestrado) - Universidade Federal do Rio Grande do Sul. Porto Alegre.

Rodrigues, C. L. P. (1993). Leis das Fábricas. Evolução da segurança do trabalho. Engenharia de Segurança do Trabalho I. Rio de Janeiro: COPPE/ UFRJ.

Roque, A. R. (2011). Palestra - Prevenção de acidente nos trabalhos em altura. Disponível em: http://www.saudeetrabalho.com.br/download/trabalturaalex.pdf Acesso 2016.

Salim, C. A. (2011). FUNDACENTRO, Saúde e Segurança de Trabalho. Aspectos Institucionais de sistema de informação e indicadores. Disponível em: http://repositorio.ipea.gov.br/bitstream/11058/3033/1/Livro_Saúde_e segurança_no_trabalho_no_Brasil_aspectos_institucionais_sistemas_de informação_e_e_indicadores Acesso 2017.

SESMT. (2012). Disponível em: Acesso em 04. Nov. 2012. Disponível em: http://repositorio.roca.utfpr.edu.br/jspui/bitstream/1/1361/1/CT_CEEST_ XXIV_2013_32.pdf Acesso 2017.

Silva, M. F. S.; Formoso, C. T.; Heineck, L. F. M. (2009). Melhorias de qualidade e produtividade: iniciativas das empresas de construção. Porto Alegre: Programa de Qualidade e Produtividade da Construção Civil no Rio Grande do Sul. 288p.

Waldheim-Neto, N. (2014). Acidente de trajeto. Goiás: Copyright 2014. Disponível em: Acesso em: 03 maio 2015.

Brasil. (2007). Ministério do Trabalho. NR-6: equipamento de proteção individual - EPI. In: Segurança e Medicina do Trabalho. 61a. ed. São Paulo: Atlas. p.73-80. 